\title{
Understanding the Impact of Digital Health Strategies During the COVID-19 Outbreak in Saudi Arabia
}

\author{
Hala Alhodaib (iD) \\ Turki M Alanzi (iD) ${ }^{2}$ \\ 'Department of Community Health \\ Sciences, College of Applied Medical \\ Sciences, King Saud University, Riyad, \\ Saudi Arabia; ${ }^{2}$ Department of Health \\ Information Management and Technology, \\ College of Public Health, Imam \\ Abdulrahman Bin Faisal University, \\ Dammam, 3|44I, Saudi Arabia
}

Background: The impact of COVID-19 has been analyzed from various aspects on the health care services management, accessibility and delivery of health care services. However, the COVID-19 pandemic has led to disruptions in health care services, which led to the increase in adoption of digital health technologies, mostly arising out of need and necessity. Objective: Focusing on the prevailing situations (increasing reliance on digital health services), this study investigates the impact of digital health technologies from the perspectives of policymakers and citizens.

Methods: A mixed-methods approach was adopted. Twenty-seven semi-structured online interviews were conducted with experts and policymakers for assessing the impact from policymakers' perspectives. An online survey questionnaire instrument was used to collect the responses from 1698 Saudi Arabian citizens in relation to the various aspects of digital health applications.

Results: Health care expenditures increased during the COVID-19 outbreak, resulting in launch of various digital health applications. While policymakers defended their stand in improving health care services and accessibility; citizens reflected inability to book medicines/personal medical equipment online (Mean=2.4) and suffered a lack of personalized care (Mean=2.9) through digital health applications. Moreover, disparities exist between the population groups with respect to the accessibility, utilization, and perceptions of digital health technologies.

Conclusion: Policymakers have to consider and address these differences in formulating digital health policies and implementing them.

Keywords: impact, digital health, strategies, COVID-19, Saudi Arabia

\section{Introduction}

The impact of novel coronavirus (SARS-CoV2) can be observed from various perspectives, such as economy, health care, socio-cultural dimension, polity,etc. Among these, health care is one of the major aspectse focused on in areas related to vaccine development, treatment options, digital health, health resources management, policies and regulations, etc. ${ }^{1-3}$ The current global situation has become complex with rising numbers of COVID-19 cases, affecting various factors of globalization. As of 4t October 2021, there are 234.8 million confirmed COVID19 cases and 4.8 million COVID-related deaths across the globe, ${ }^{4}$ and no improvement in these numbers has been observed in the past few months. However, there is a positive trend observed during the COVID-19 outbreak in relation to the adoption
Correspondence: Turki M Alanzi Department of Health Information Management and Technology, College of

Public Health, Imam Abdulrahman Bin

Faisal University, King Faisal Road,

Dammam, 3|44I, Saudi Arabia

$\mathrm{Tel} / \mathrm{Fax}+966$ I3333/2II

Email talanzi@iau.edu.sa 
of digital health technologies, which increases the efficiency and effectiveness of the health care operations and service delivery. A shift from traditional health care operations to digital health operations in few countries; and a rapid increase in the adoption of digital health in some countries which have already deployed digital health was observed during the outbreak. ${ }^{5}$ For example, Saudi Arabia has been rapidly adopting digital health technologies for managing health care operations and improving quality of service and delivery. ${ }^{12}$ As a result, there has been a significant reduction in the number of COVID-19 cases in the kingdom since July 2020; however, the number of COVID-related deaths has been stagnant, with no significant reduction observed since July 2020. ${ }^{6}$ This might indicate that Saudi Arabia has been effective in adopting mitigation strategies to prevent virus transmission, but not very effective in addressing the impact of COVID-19 on citizens' health and health care operations. For instance, less preference for physicians adopting telemedicine, ${ }^{46}$ lack of proper management of work burden and stress on health care practitioners, ${ }^{4,48}$ were few such issues that highlight the ineffectiveness of the strategies adopted. In this context, the impact of COVID-19 can be observed in areas related to access and administration, operations, and personalization in Europe, the Middle East, and African regions. ${ }^{5}$ In terms of access and administration, it was observed that there is a rapid increase in the adoption of digital health technologies such as telehealth over short-periods, resulting in limited supply and uneven access between various groups of the population (rural/urban; educated/uneducated), globally. ${ }^{7}$ In terms of operations, availability of technology solutions in various operations such as supply chain, logistics and resource management differed across countries, and accordingly the impact of COVID-19 was addressed. ${ }^{5,8}$ In terms of personalization, such as condition-based digital health (for example, remote patient monitoring, disease-specific diagnosis and monitoring systems, etc.) are yet to be improved and developed to ensure the safety of patients through remote health care services. ${ }^{5,11}$ Other aspects such as socio-cultural issues were also identified. ${ }^{9}$ It was highlighted that it is equally important to consider the societal dimensions while paying attention to scientific knowledge, technical innovation, and investments in digital health technologies. ${ }^{9}$ For example, the societal aspects such as culture, traditions, and also the socio-economic impact on genders, distribution of cases, etc. are some impacts of COVID-19 10 which need to be considered when implementing digital health technologies and digital health policy formulation.

Considering the impact of COVID-19 on these aspects, this study aims to assess the impact of digital health strategies on COVID-19 outbreak in Saudi Arabia, where rapid digitalization of health care operations is under progress, ${ }^{12}$ and a strong influence of culture and traditions can be observed. ${ }^{13,14}$ Assessing the impact in these two contexts can help in analyzing the gaps in the implementation of digital health technologies between the policymakers or government and the service receivers or citizens. The impact was assessed from two perspectives: policymakers and citizens; focusing on the key health care operational areas including health care expenditures, resources management, service quality, service delivery, information management, relationship management, and COVID-19 awareness programs. Accordingly, the methods adopted in the assessment, results, and the discussion are presented in the following sections.

\section{Methods}

The purpose of this study is to understand the impact of digital health strategies during COVID-19 outbreak in Saudi Arabia. To achieve this objective, a mixed methods approach including both online surveys and online semistructured interviews were adopted for data collection. As quantitative surveys can be a useful instrument in effectively collecting data from large sample population and generalize findings, it is used for collecting data from Saudi citizens in relation to the digital health services. In addition, semi-structured interviews were conducted with digital health experts and policymakers The Institutional Review Board at Imam Abdulrahman Bin Faisal University approved the ethical protocol of this research. Anonymity of the participants is ensured in this study and informed consent was obtained from the participants for their participation in this study and for the publication of anonymized responses.

\section{Survey}

\section{Questionnaire Design}

The data collection through the survey questionnaire is aimed at five major aspects of digital health impact on users, which include accessibility (information, resources, and services), usability, health care expenditures, service quality, and awareness (related to digital health and COVID-19). There are four items in this category relating to accessibility of health information, booking 
appointments, booking medicines/medical equipment, and personalized care. With the developments in social media, the Internet and communication technologies, people are increasingly relying on the web to accessvarious services. ${ }^{15,16}$ However, the accessibility of services may vary across regions depending on people's ICT skills and the availability of online services. ${ }^{17}$ In relevance to these studies, ${ }^{15-17}$ the four items in the accessibility category were formulated. Five items were included in the usability category, which are related to ease of use and usefulness from mHealth App Usability Questionnaire. ${ }^{18}$ Digital health technologies may reduce the health care expenditures of people, ${ }^{19}$ based on two items included in the health care expenses category. Four items related to reliability, readiness, safety, and empathy were included in service quality category, that were derived from ServiceQual model. ${ }^{20}$ In addition, two items relating to health awareness and COVID-19 awareness are included in the awareness category of the survey questionnaire. Each item in the survey questionnaire was rated on a scale of $1=$ strongly disagree to $5=$ strongly agree, based on the Likert scale. ${ }^{21}$ The questionnaire was initially developed in English, which was later translated into Arabic by two professional translators. The two translated versions were rechecked by authors for every statement that differed in the two versions. Disagreements were sorted through discussions until a mutually agreed single translated copy of the questionnaire was formulated. A pilot study was conducted with a sample of 16 people ( 5 businessmen, 6 graduate students, 5 health workers). Cronbach's alpha for all items in five categories was identified to be greater than 0.86 , indicating reliability and consistency.

\section{Recruitment and Sampling}

The final translated version of the survey questionnaire was uploaded on QuestionPro application, and a survey link was generated. The survey was targeted at Saudi citizens to assessthe impact of digital health technologies on their health needs during the COVID-19 outbreak. The survey link was initially forwarded to the contacts of authors through WhatsApp, Facebook, and emails. The link was also posted on community pages on various social media networks. In addition, a snow-ball sampling technique $^{22}$ was used to reach a larger section of population, by placing a note in the message attached to the survey requesting that the participants forward the message to their contacts, friends, and family. The participants were provided with information, the purpose of survey and where they need to provide their consent to the participation by clicking "I Agree" to the terms specified. Furthermore, it is mentioned in the information that the survey only needed to be completed by Saudi Arabian citizens. Participants were assured of anonymity and safety and privacy in accordance with ethical practices in research. The survey link was active from 16 October 2020 to 15 December 2020, providing adequate time for gathering responses from a larger section of the Saudi Arabian population. A total of 2271 responses were collected in a period of four weeks. Out of 2271 responses, 573 responses were incomplete, as a result of which a final sample of 1698 was considered in this study.

\section{Semi-Structured Interviews Questionnaire Design}

As semi-structured interviews are flexible for adding new questions during the interview, the initial interview questionnaire had similar categories as those in survey questionnaire, but from the perspective of policymakers or government-implemented digital health technologies. Accordingly, the interview questionnaire included seven primary questions assessing the impact of digital health technologies on health care expenditures, resource management, service delivery, information management, service quality, relationship management, and creating awareness.

\section{Recruitment and Sampling}

Semi-structured interviews were conducted with the purpose of assessing the impact of digital health technologies on the government and policymakers. Accordingly, the participants for interviews were recruited using a purposive sampling approach. ${ }^{24}$ In this context, a variety of professionals working under Ministry of Health $(\mathrm{MOH})$, and other public hospitals were contacted for their participation in the interviews. The final sample population for the interviews achieved was 27, and their details are presented in Table 1. Interviews were conducted using Zoom individually with each interviewee. Out of the 27 participants, 11 (40.7\%) were senior physicians working in public hospitals, $12(44.4 \%)$ participants were senior managers working under $\mathrm{MOH}$ in the planning and implementation department, and four (14.8\%) were senior executives in the $\mathrm{MOH}$. Focusing on the demographics of interviewees, there were more male interviewees than female interviewees. The majority of the interviewees 
Table I Frequency Distribution of Key Variables of Survey Participants

\begin{tabular}{|l|l|l|}
\hline Variables & Survey n (\%) & Interviews n (\%) \\
\hline $\begin{array}{l}\text { Gender } \\
\text { Male }\end{array}$ & $990(58.3 \%)$ & $16(59.2 \%)$ \\
Female & $708(41.7 \%)$ & $1 \mathrm{I}(40.8 \%)$ \\
\hline Age & & \\
I8-24 & $215(12.7 \%)$ & N.A \\
$25-34$ & $77 \mathrm{I}(45.4 \%)$ & $3(11.1 \%)$ \\
$35-44$ & $553(32.6 \%)$ & $9(33.3 \%)$ \\
$45-54$ & $132(7.7 \%)$ & $11(40.7 \%)$ \\
$>54$ & $27(1.6 \%)$ & $4(14.8 \%)$ \\
\hline Education & & \\
Diploma & $283(16.7 \%)$ & N.A \\
Bachelor's Degree & $847(49.9 \%)$ & $6(22.2 \%)$ \\
Master's Degree & $334(19.7 \%)$ & $17(63.0 \%)$ \\
Ph.D. & $23(1.3 \%)$ & $4(14.8 \%)$ \\
Others & $211(12.4 \%)$ & N.A \\
\hline Employment & & \\
Employed & $1146(67.5 \%)$ & $27(100 \%)$ \\
Unemployed & $552(32.5 \%)$ & N.A. \\
\hline Work Experience & & \\
< 2 years & $134(7.9 \%)$ & N.A \\
$2-5$ years & $350(20.6 \%)$ & $2(7.4 \%)$ \\
$5-10$ years & $632(37.2 \%)$ & $18(66.7 \%)$ \\
$>10$ years & $582(34.3 \%)$ & $7(25.9 \%)$ \\
\hline
\end{tabular}

were identified in the age group of 45-54 years, followed by 35-44 years. Most of the participants had a Master's qualification, and had work experience between 5-10 years.

\section{Data Analysis}

Both survey and interviews data were used for analyzing the findings, as they complement each other from two different perspectives. Interviews were recorded in Arabic, which are later transcribed into English language using NVivo software. The converted transcripts were thoroughly read by authors for any mistakes in the meaning of sentences and grammar, and were improved accordingly. Interview data was analyzed in the context of this study (assessing the impact of digital health technologies) from the perspective of policymakers by identifying the most important codes and statements that are grouped under the seven categories, including health care expenditures, resources management, service delivery, information management, service quality, relationship management, and creating awareness. In addition, average ratings for each item in the survey questionnaire were calculated, and were grouped by age and gender (as applicable based on the category) for in-depth analysis. The survey results are presented in relation to the seven categories mentioned above, an outcome of which is that results and discussion can be presented for each category from the perspective of digital health implementers and users.

\section{Results and Discussion}

The demographic information of the participants is presented in Table 1. A slightly greater number of male participants were observed in the sample compared to female participants. The majority of the participants belonged to the 25-34 years age group, followed by the 35-44 years age group, indicating that the sample comprised of a young population, who may be more inclined towards the adoption of digital health. ${ }^{23}$ Most of the participants $(49.9 \%, 847 / 1698)$ held a Bachelor's degree, followed by a Master's degree (19.7\%, 334/1698), and a diploma (16.7\%, 283/1698), indicating a good representation of the educated population in the sample. The majority of the participants $(67.5 \%, 1146 / 1698)$ were employed. However, work experience was reflected by 1224 (72.1\%), indicating few unemployed and retired population who had previous work experience.

The results in relation to various categories for analyzing the impact are presented in the following sections.

\section{Health Care Expenditures}

Interview results in this category have indicated an increase in health care expenditures due to the rapid development and implementation of digital health tools in order to combat the COVID-19 outbreak and ensure continuity in delivering better health care services. Most of the funding in digital health implementation was through the privatization of health care services, which can be inferred from the following statement from a senior executive at $\mathrm{MOH}$ :

As a part of Vision 2030, Saudi government has adopted health care privatization policy to bring in state-of-art health care technologies and services to cater the health care needs of Saudi Arabian population.

However, privatization may not largely benefit the majority $(75 \%)$ of the population who are dependent on public health care services, while only $25 \%$ of the population is dependent on private health care services. ${ }^{25}$ As a result of huge demand, and the ongoing COVID situation, there is a huge surge in health care expenditure, owing to an 
increased need for health care resources and operations, which is evident from the following statement by a senior physician from one of the public hospitals.

There has been an increased utilization of resources, including medical equipment, nurses, physicians, etc., in the past few months, which resulted in a surge in expenditures than normal.

Though measures were being taken to addressthe health care concerns of all the citizens by launching insurance and privatization schemes, ${ }^{25}$ there may be a burden on citizens in accessing the necessary health care services due to the growing demand. Accordingly, the survey results have indicated that there is little reduction in health care expenditures (Mean $=3.1, \mathrm{SD}=1.5$ ), and not much reduction in health care expenditures for expenses incurred by traveling (Mean $=2.9, \mathrm{~S} . \mathrm{D}=1.4$ ) to outpatient blocks in hospitals, as shown in Figure 1. It can be observed that the majority of the participants who opined that they did not save much from hospital visits are older than 44 years of age. This might be attributed to the increase in likelihood and prevalence of chronic diseases among this age group in Saudi Arabia. ${ }^{26,27}$ Furthermore, males (Mean=3.2, $\mathrm{SD}=1.12$ ) agreed they saw a reduction in health care expendituresin slightly higher numbers when compared to female participants (Mean=3.0, $\mathrm{SD}=1.16$ ), and no significant difference was observed between male and female participants in terms of reduced expenses in traveling.

Therefore, though there is an increase in health care expenditure owing to the implementation of digital health from the perspective of policymakers, there is no significant reduction in the health care expenditures among citizens while accessing digital health technologies.

\section{Resources Management}

Managing health care resources, especially the frontline health care workers safety and also the patients with critical illness, are few major challenges affecting the delivery of health care services, as it requires effective, safe, and efficient strategies. ${ }^{28-30}$ Focusing on these aspects, the senior manager working for the $\mathrm{MOH}$ stated that:

There has been increase in the imports of necessary medical equipment for the management of COVID-19 in Saudi Arabia. While we are focusing on mitigation strategies, we are equally focusing on ensuring the access to all those who are infected with COVID, and also those with critical illness requiring regular care, by adopting safe practice standards.

However, a physician from one of the public hospitals stated that:

There is an increased stress on the health care workers owing to increased working hours, and there is a slight gap in the supply of essential medical equipment in accordance with the growing demand, due to the disruptions in the supply chain because of COVID restrictions and safety procedures.

In addition, resources related to digital health saw few observed issues. Most of the interviewees (15/27) observed that there is a lack of complete integration of

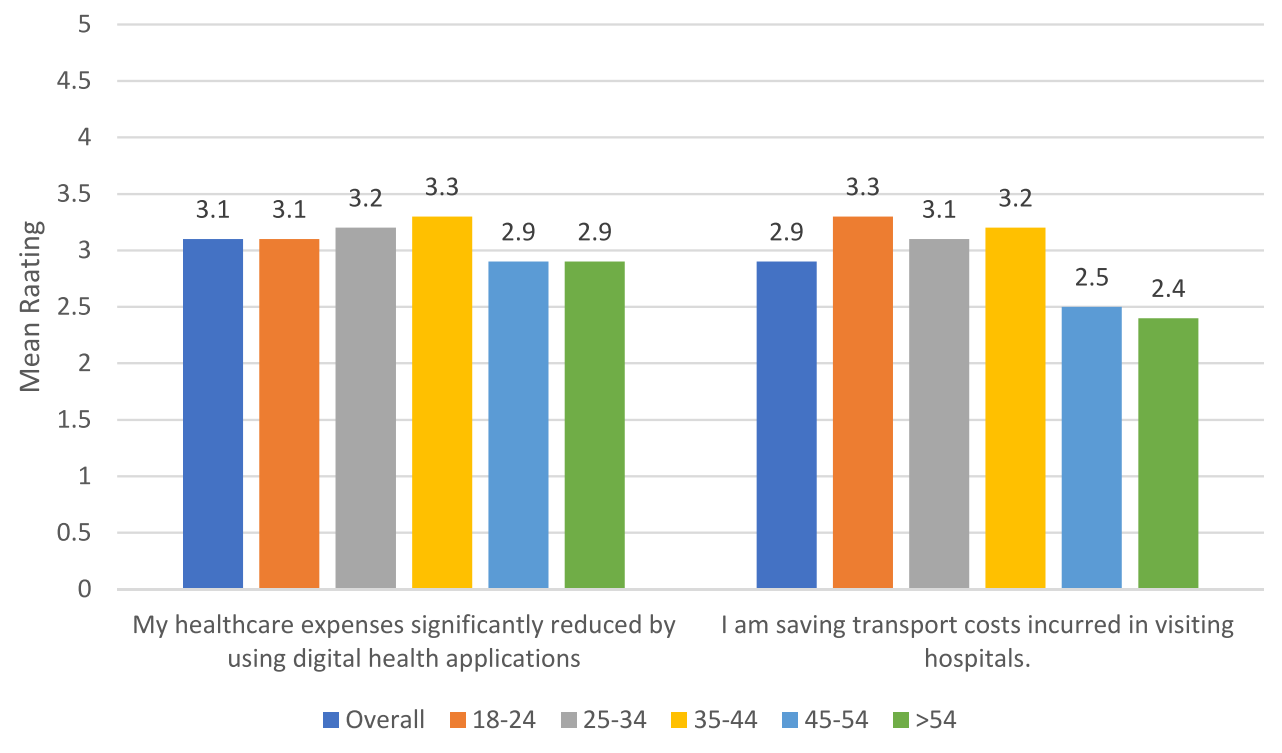

Figure I Mean ratings of items related to health care expenditures by different age groups. 
digital health technologies in public hospitals, which can be inferred from a senior physician's statement:

We are in the process of integrating major hospitals with primary care centres and polyclinics with information and communication technologies, ensuring real-time access to all types of health-related data. This would not only help patients in accessing services, but also physicians in providing efficient and effective care. However, due to COVID, the integration process has slowed down, and the burden of delivering services has increased due to issues associated with patients' historical data.

It is evident that the health care system in Saudi Arabia is currently in a transition phase moving towards a more sustainable and digitized health care system, deploying the most effective technologies. However, the current situation and the delays caused by theCOVID-19 outbreak may increase the health care budget, its associated costs, and the delivery of health care services due to issues identified with resource management.

\section{Service Delivery}

There have been various issues identified with the delivery of health care services due to the COVID-19 outbreak, especially in delivering critical care services, and formulating clinical guidelines. ${ }^{31,32}$ Digital health technologies such as mobile health applications ${ }^{33,34}$ were effective to an extent in delivering primary health care services, reducing the burden on an already strained health system. The $\mathrm{MOH}$ has launched various mobile applications such as Seha, Tabaud, Tawakkalna, Tataman, Mawid, Ashanak, and Mawared $^{35,36}$ for delivering essential health care services such as e-consultation, booking appointments, etc. Accordingly, one of the executives in the MOH stated that:

There are multiple mobile health applications being launched by $\mathrm{MOH}$, which are aimed at various health care services, and it may take time for users to adopt it, as the change cannot happen overnight.

The statement reflects that there has been a drastic change in the delivery of health care services by relying more on digital health than traditional health services due to COVID-19. However, this change is sudden and the $\mathrm{MOH}$ has to ensure its smooth implementation. In this context, when cross-questioned "if creating multiple applications can lead to ambiguity among the users in accessing services," the executive responded that:
Certainly not. The purpose of each application has been clearly defined. Some applications provide multiple services such as consultation, e-permits, while others focus only on appointment booking. We are trying to integrate services. For example, Mawid application can be used to book appointments at any primary care centre throughout Saudi Arabia.

Though the reply was not convincing enough, there is an ongoing process to integrate health care services in mobile applications to enable easy access.

In this context, the survey results related to service access have reflected average impact of digital health technologies, slightly contradicting the interview responses, as shown in Figure 2. The ability to book appointments was the highest rated aspect (Mean $=3.9$, $\mathrm{SD}=1.2$ ), followed by access to health-related information $($ Mean $=3.6, \mathrm{SD}=1.2)$. Access to booking medicines online, and access to personalized care were two aspects which are rated low, revealing the inefficiency of digital health technologies in providing these services.

Females reflected lower ratings compared to males in relation to all services that are accessible. Analyzing by age groups, aged population ( $>44$ years) reflected lower levels of access compared to young population, as shown in Figure 3; thus, indicating the young population is better at accessing digital health services compared to the older population. $^{37}$

\section{Information Management}

Information is one of the most important resources for effectively managing health care operations and delivering health care services. Various types of information such as inpatient and outpatient records, diagnosis and imaging records, standards and guidelines, information related to health care process, operations, etc. have to be effectively managed for streamlining health care operations. Implementation failures, lack of effective health policies, and standards are few issues identified with information management in Saudi Arabia. ${ }^{38}$ In this context, one of the executives in the $\mathrm{MOH}$ stated that:

It is true that there are challenges in managing healthrelated information in the Kingdom, which is why the policies of privatization and digitization have been introduced in Vision 2030. As I said earlier, we are in the process of transformation.

When cross-questioned about the steps being taken, the executive replied: 


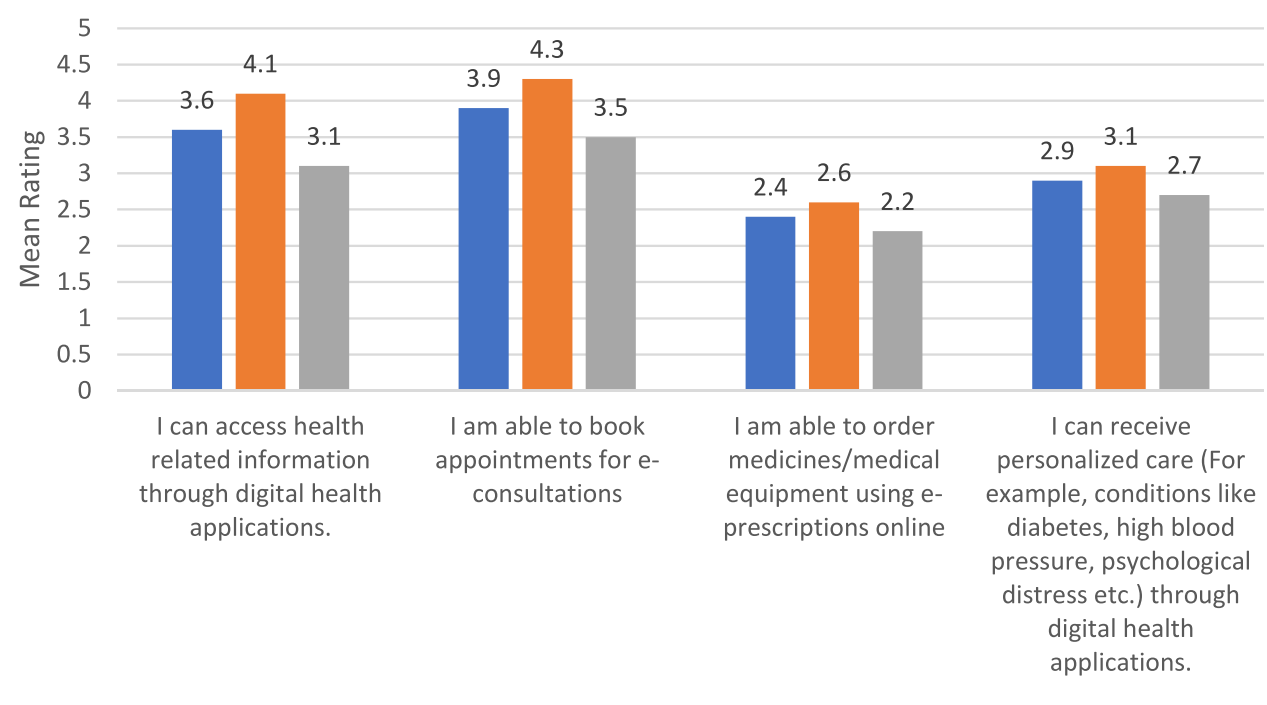

- Overall Male Female

Figure 2 Mean ratings of items related to health care services accessibility by different genders.

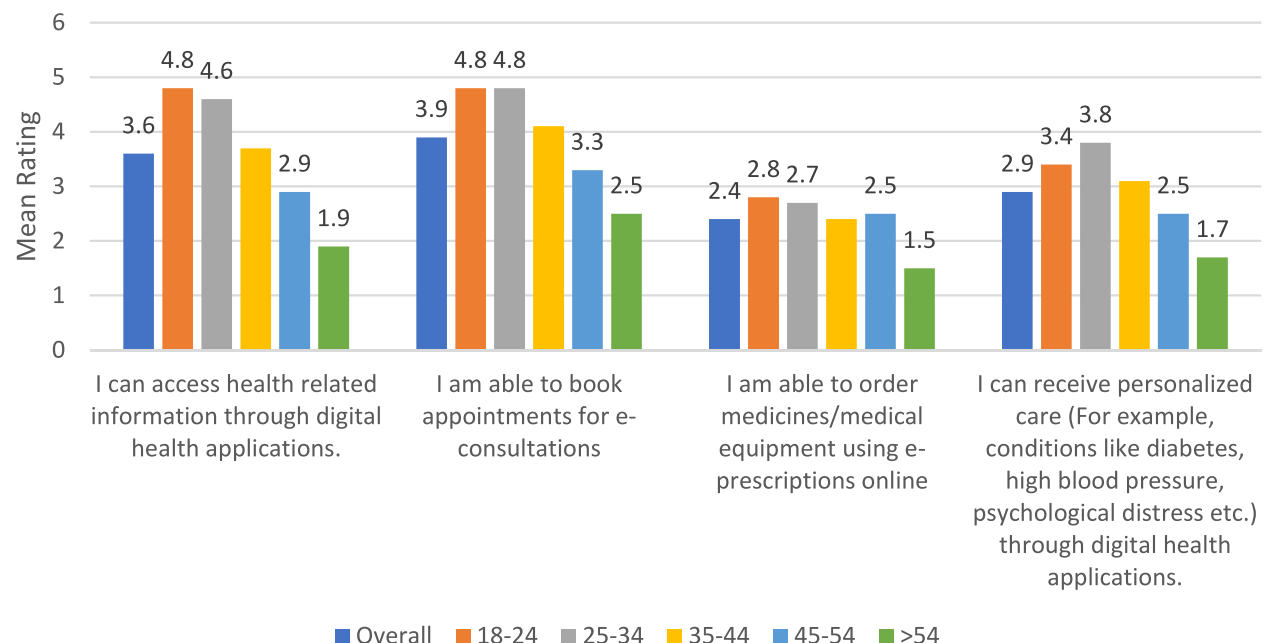

Figure 3 Mean ratings of items related to health care services accessibility by different age groups.

We are working with various organizations in establishing international level standards and regulations, which are accordingly being considered in the development and implementation of digital health technologies. One of the challenges is lack of awareness about the benefits of electronic health information management among Saudi citizens. We are implementing awareness campaigns and encouraging citizens participation in digital health services; and also using advanced technologies for addressing the concerns about privacy and security.

Accordingly, the majority of interviewees (21/27) agreed socio-cultural and technological issues and lack of awareness affected the implementation of digital health technologies. Accordingly, studies have proposed the centralization of the health information system through cloud computing, ${ }^{39}$ increased implementation of electronic health records, ${ }^{40}$ and addressing technological issues in migrating to advanced systems, ${ }^{41}$ etc.

\section{Service Quality}

Service quality is an important factor which reflects the health care services standards and efforts of policymakers towards health care delivery. The analysis of interview data revealed that all the interviewees (27/27) strongly emphasized the need for good quality care in the health care industry. Focusing on this aspect, a senior physician stated that: 
Quality is utmost priority for us in this hospital. Our hospital policies clearly reflect the importance towards service quality. Be it appointments management or quality of medical equipment or safety standards or patients' relationships. Quality is one of the important criteria to be followed in every single operation or process.

Another physician, however, mentioned that delivering high quality services using digital technologies can be challenging. As the citizens are slowly adopting digital health technologies, and a sudden surge in the demand due to COVID-19, ensuring good quality service and achieving patients' satisfaction, has become some of the challenging tasks. With lack of awareness, using digital health technologies for acute conditions can be risky for patients, as well as physicians.

The results from the survey analysis were found to be in accordance with interviews analysis. While digital health services were identified to reliable by the majority, issues such as safety and security, and inability to provide personalized care were highlighted as shown in Figure 4.

There are a considerable and significant differences in the perceptions of service quality of digital health technologies between men and women participants. Male participants, when compared to female participants, perceived digital health services to be more reliable, ready to provide services, and to be safe and secure.

In addition, older participants reflected concerns over safety and security, lack of personalized care, readiness of services, and reliability in contrast with younger participants as shown in Figure 5. Therefore, there is a disparity in the beliefs and perceptions of digital health services among various age groups in Saudi Arabia.

\section{Relationship Management}

Ensuring good relations with patients, partners, and stakeholders is essential in managing and delivering health care services. In this context, the Saudi Arabian health care system has various stakeholders, including private and public hospitals' management, investors, pharmacies, NGOs, technology partners, international health organizations, citizens, etc. In relation to the relationship management with stakeholders, one of the executives at the MOH stated:

Our approach to ensuring good relations with stakeholders in health care system focuses on engaging stakeholders in communication in realizing the Saudi Vision 2030 goals, with a service-oriented philosophy of delivering care through effective and efficient technologies, and encouraging mutual benefits.

Similarly, one of the physicians stated that:

We need to ensure adoption of good relations with other hospital units for better delivery of care. The success in delivering good care to patients lies in maintaining good relations with all stakeholders of health care system, as each component can impact the operations of other component.

As the various entities in the health care system are interdependent, there is a need for cooperative and collaborative relations in managing health care operations, motivated by the goal of delivering effective and efficient health care services with patients at its heart. RThe majority of the interviewees (16/27) stated that the relationship between the stakeholders is being improved with the adoption of

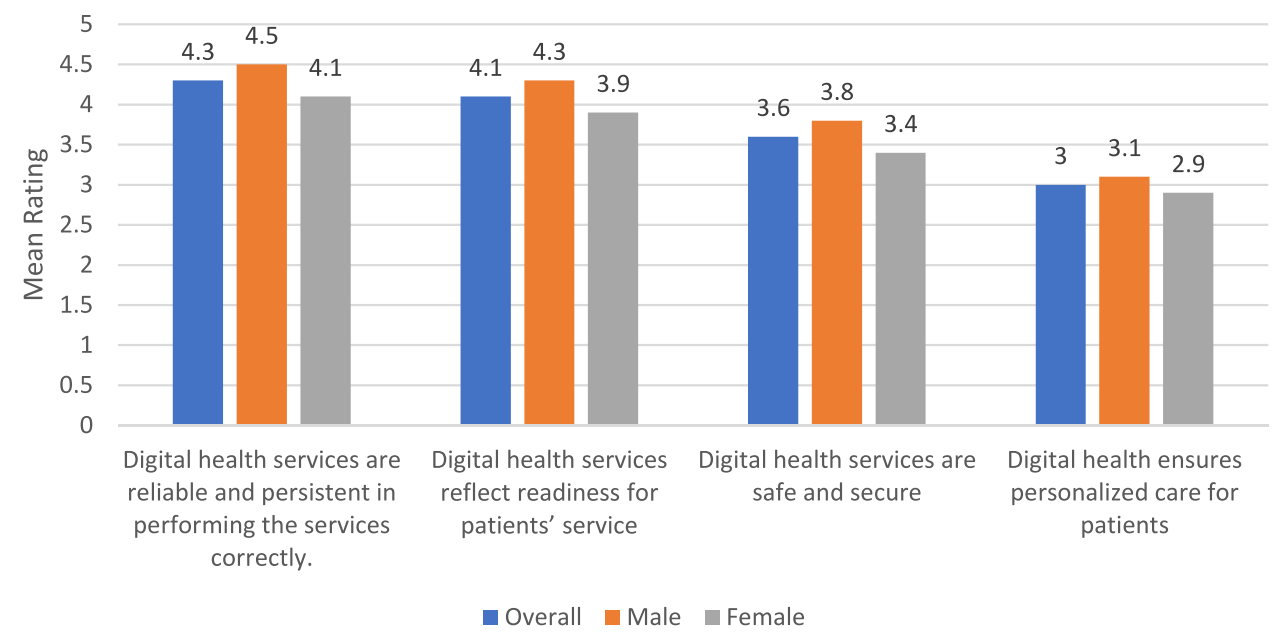

Figure 4 Mean ratings of items related to health care services quality by different genders. 


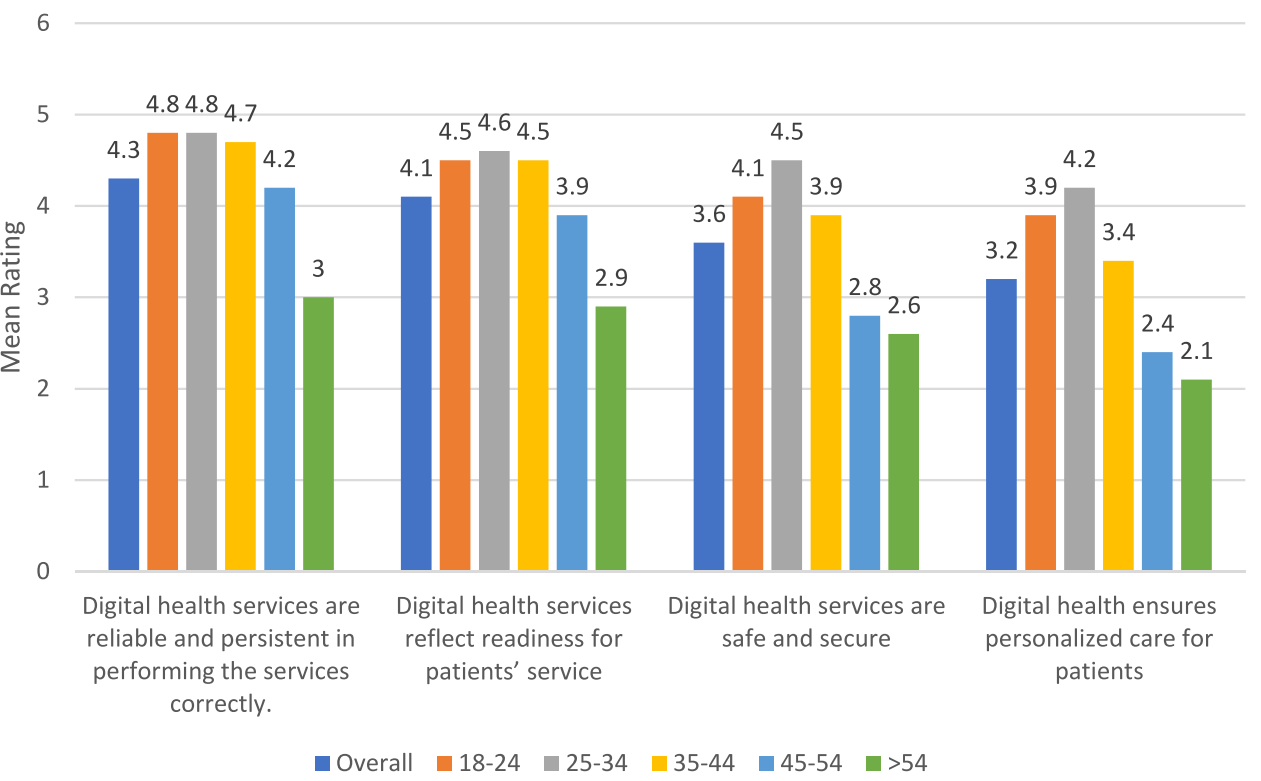

Figure 5 Mean ratings of items related to health care services quality by different age groups.

new strategies and implementation of innovative technologies. However, recent studies ${ }^{42,43}$ have revealed various factors influencing stakeholder relationships. Significant influence of government regulations, competitors, suppliers, patients, the public, and health service providers, was identified in developing the Saudi health care system, which can be addressed by creating awareness among stakeholders. ${ }^{42}$ In addition, changes in the governance structure, gradually increased autonomy from the government, lack of accountability in hospitals, and cooperative relationships between cluster hospitals were identified. ${ }^{43}$ Though the importance of digital health services is realized for improving relationships between stakeholders, there are few issues as identified from the above studies affecting the process of relationship management. These factors might further affect the delivery of health care services, which in turn affects the usability and the relationship of care providers with citizens.

In this context, survey results have revealed that the digital health technologies are easy to use, and their benefits are largely realized by the participants, as shown in Figure 6. However, average levels of satisfaction (Mean $=2.9, \mathrm{SD}=$ 1.6) with respect to these technologies was identified.

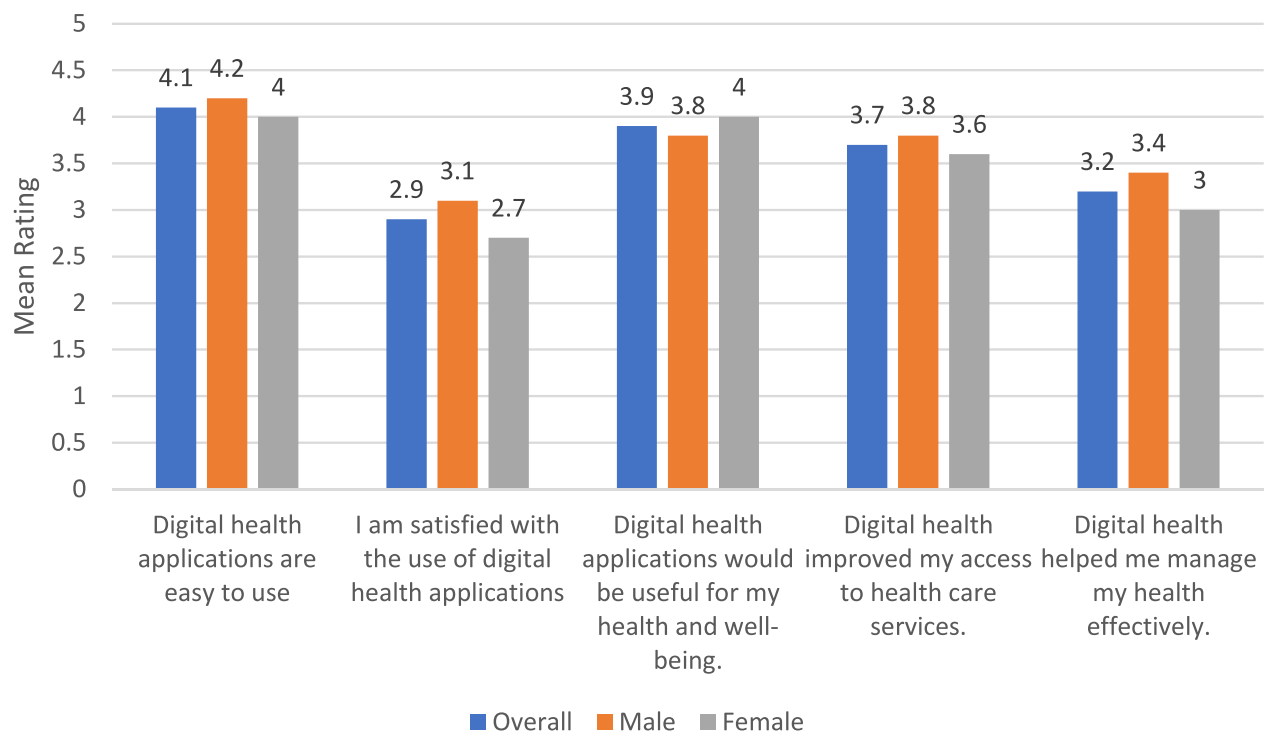

Figure 6 Mean ratings of items related to digital health usability by different genders. 


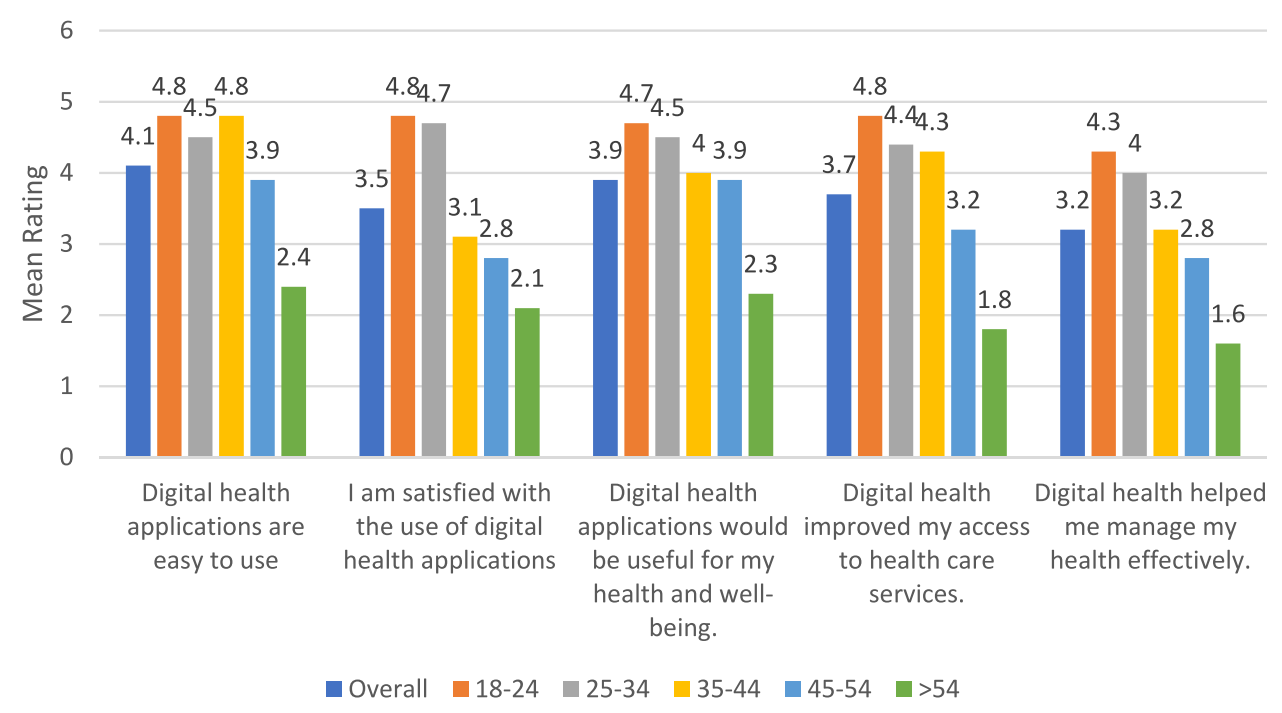

Figure 7 Mean ratings of items related to digital health usability by different age groups.

The average levels of satisfaction (as shown in Figure 6) can be further correlated with issues in accessing health care accessibility, such as lack of personalized care specified in Figure 2. Differences of opinions can be observed between male and female participants. Male participants were slightly more satisfied and believed that health can be effectively managed with digital health applications, than were female participants.

Analyzing the findings (in Figure 7), it can be observed that there is a significant difference in the usability aspects of digital health applications between the older participants ( $>$ 44 years) and younger participants. Ease of use, satisfaction, and realization of benefits of digital health technologies were identified to be low among older participants compared to younger participants, further indicating the generalizability issues and irregular adaptability in digital health technologies.

\section{Awareness}

Awareness creation is an important aspect in the process of transforming the health care system from a traditional model to a digitized model, especially in the current situation of COVID-19, where the reliance on eHealth is increasing rapidly. In this context, the majority of the interviewees (25/ 27) acknowledged the need for creating awareness among the Saudi citizens about benefits in using digital health services. However, one of the senior managers in the $\mathrm{MOH}$ stated that:

Due to the sudden emergence of COVID-19, the planned processes in digital transformation, especially awareness campaigns were affected and had to be reorganized and planned.
It is clear from the above statement that there is a need to create awareness and promote the use of digital health services in Saudi Arabia. In this context, one of the physicians stated that:

We are almost completed in the digitalization of health care services in our unit, but the patients' turnout in using these services is low. Most of the patients were using these applications for booking appointments at hospitals rather than appointments for e-consultations.

In addition, focusing on the role of digital health technologies in creating awareness, one of the senior managers from the $\mathrm{MOH}$ stated that:

Some of the applications launched during the COVID outbreak were integrated with the features of creating awareness by sharing educational information and notifications through the mobile and web applications.

It can be observed that eHealth applications launched by the government are being misinterpreted by the citizens, as they are being used for outpatient appointments, though they provide e-consultation services. There can be various reasons for this behavior, such as lack of trust, concerns over privacy and security, inconvenience in communicating online, etc. Such issues have to be addressed by launching awareness campaigns, and educating the people, especially those in rural areas. Similar results with respect to lack of awareness were identified in other studies. ${ }^{44,45}$ It is also essential that the individuals need to promote and create awareness though social networking sites and other modes of communication in order to address the 
challenges of health care services delivery in the current situation. In addition, the initiatives from $\mathrm{MOH}$ such as integrating mobile health applications developed for e-consultation and other services with awareness creation features is an effective and cost-saving promotional strategy that can directly reach targeted section of population.

In this context, survey results as shown in Figure 8, have revealed that the majority of the participants (Mean = $3.8, \mathrm{SD}=1.4$ ) digital health applications are effective in creating awareness about maintaining good health; and also in educating patients about COVID-related information and safety procedures $($ Mean $=3.5, \mathrm{DD}=1.2)$.
However, significant differences in perceptions existed between male and female participants, where male participants rated higher than female participants with regard to the ability of creating awareness by digital health applications as shown in Figure 8.

In relation to the age groups (Figure 9), there were no significant differences identified between the different age groups in relation to the awareness creation by digital health applications, except the age group including participants aged more than 54 years. Thus, it can be inferred that digital health applications can be effective in creating awareness

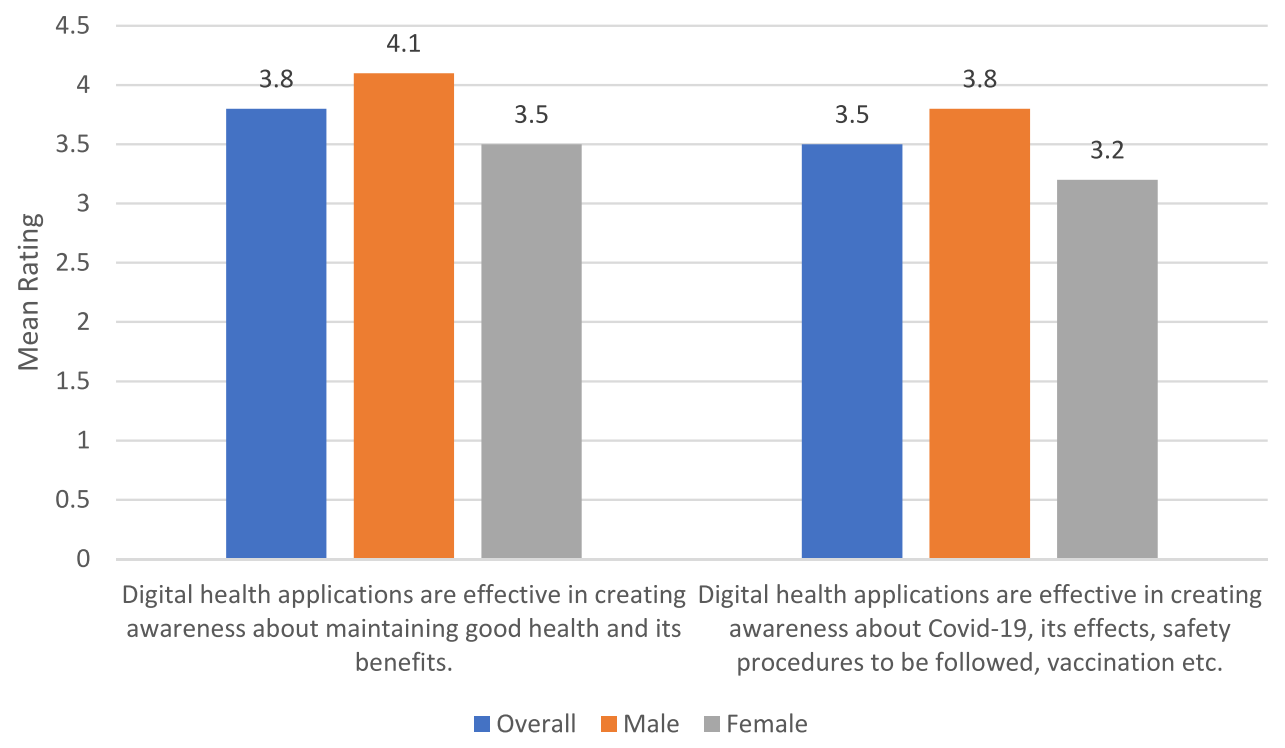

Figure 8 Mean ratings of items related to digital health applications in creating awareness: by different genders.

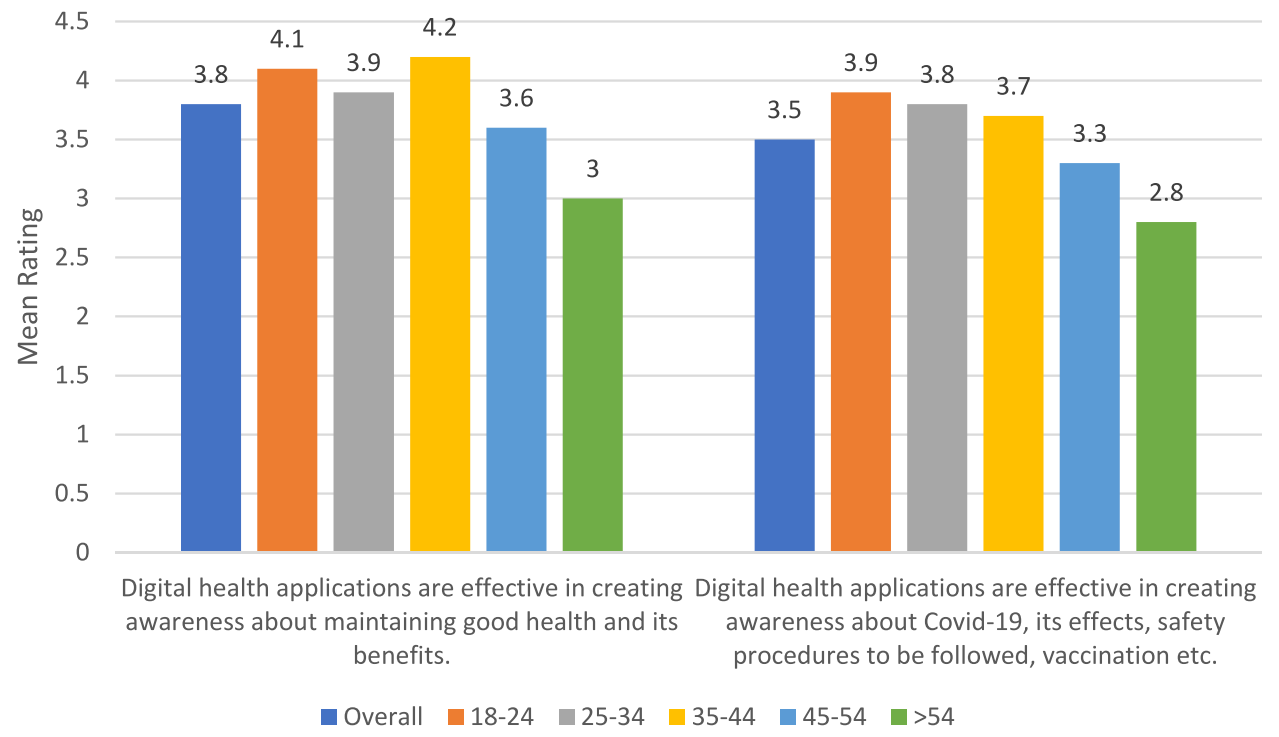

Figure 9 Mean ratings of items related to digital health applications in creating awareness: by different age groups. 
about COVID-19 and the benefits of using them for maintaining good health.

\section{Conclusion}

In accordance with the aim of this article, this study has deployed semi-structured interviews and surveys to collect the data related to the impact of digital health strategies during COVID-19 from the perspectives of policymakers and citizens respectively. Various assessments can be inferred from the findings. First, health care expenditures of the government have increased due to COVID-19; however, no significant reductions in the health care expenditures were observed with citizens by deploying digital health applications. Second, the health care system, though under stress, is deploying various strategies to effectively manage resource utilization, and meet the supply demand ratio in relation to the digital health. Third, government have launched various mobile health applications to address the health care needs of patients; however, citizens have found them to be useful only in certain aspects, as they were to be ineffective in some services such as providing specialized personal care. Fourth, various initiatives were being undertaken for improving the information management in the health care system; however, there are still few issues identified because of the transition phase of health care model from traditional to digitalized. Fifth, service quality was identified to be the utmost priority of the policymakers; and accordingly, the citizens have rated digital health services quality to be good. Sixth, the policymakers are adopting a systematic and strategic approach in improving relationships with all stakeholders, especially with technology companies in speeding-up the digitalization of services in the current times of utmost need. Relating the relationships with patients in their accessibility and usage of digital health applications, it was identified that majority were neither satisfied nor dissatisfied and raised concerns over safety and security, which might affect their adoption of digital health technologies and in turn their relationship with the health care system. Lastly, there were delays experienced in creating awareness about digital health services by the policymakers due to the COVID-19 outbreak; however, citizens were identified to be accessing health-related and COVID-related information through digital health applications launched in the Kingdom in the past few months. In addition, in most of the contexts, male participants and young participants were more inclined in using digital health applications compared to older participants. Based on the findings, it can be concluded that minor differences exist in the perceptions of policymakers in relation to the impact of digital health technologies during COVID-19, and the Saudi Arabian citizens' perceptions. Moreover, disparities exist between the population groups with respect to the accessibility, utilization, and perceptions of digital health technologies. As a result, policymakers have to consider and address these differences in formulating digital health policies and implementing them.

\section{Disclosure}

The authors report no conflicts of interest in this work.

\section{References}

1. Alanezi F. Factors affecting the adoption of e-health system in the Kingdom of Saudi Arabia. Int Health. 2020;13(5):ihaa091. doi:10. 1093/inthealth/ihaa091

2. Teo CL, Chee ML, Koh KH, et al. COVID-19 awareness, knowledge and perception towards digital health in an urban multi-ethnic Asian population. Sci Rep. 2021;11(1):10795. PMID: 34031469; PMCID: PMC8144201. doi:10.1038/s41598-021-90098-6

3. Nurunnabi M. The preventive strategies of COVID-19 pandemic in Saudi Arabia. J Microbiol Immunol Infect. 2021;54(1):127-128. doi:10.1016/j.jmii.2020.07.023.

4. World Health Organization. WHO Coronavirus disease (COVID-19) dashboard [Internet]. Covid19.who.int; 2020 [cited October 5, 2021]. Available from: https://covid19.who.int/. Accessed November 2, 2021.

5. Koh D. COVID-19 has pushed digital health forward, but challenges still persist [Internet]. Healthcare IT News; 2020 [cited December 17, 2020]. Available from: https://www.healthcareitnews.com/news/ emea/covid-19-has-pushed-digital-health-forward-challenges-stillpersist. Accessed November 2, 2021.

6. World Health Organization. WHO Coronavirus disease (COVID-19) dashboard: Saudi Arabia [Internet]. Covid19.who.int; 2020 [cited December 17, 2020]. Available from: https://covid19.who.int/ region/emro/country/sa. Accessed November 2, 2021.

7. Gunasekeran DV, Tseng RMWW, Tham YC, Wong TY. Applications of digital health for public health responses to COVID-19: a systematic scoping review of artificial intelligence, telehealth and related technologies. NPJ Digit Med. 2021;4(1):40. PMID: 33637833; PMCID: PMC7910557. doi:10.1038/s41746-021-00412-9

8. Leite H, Lindsay C, Kumar M. COVID-19 outbreak: implications on healthcare operations. TQM J. 2020;33(1):247-256. doi:10.1108/ TQM-05-2020-0111

9. Bayram M, Springer S, Garvey C, Özdemir V. COVID-19 digital health innovation policy: a portal to alternative futures in the making. OMICS. 2020;24(8):460-469. doi:10.1089/omi.2020.0089

10. Burki T. The indirect impact of COVID-19 on women. Lancet Infect Dis. 2020;20(8):904-905. doi:10.1016/S1473-3099(20)30568-5

11. Mayor S. COVID-19: impact on cancer workforce and delivery of care. Lancet Oncol. 2020;21(5):633. doi:10.1016/S1470-2045(20) 30240-0

12. Hassounah M, Raheel H, Alhefzi M. Digital response during the COVID-19 pandemic in Saudi Arabia. J Med Internet Res. 2020;22 (9):e19338. doi:10.2196/19338

13. Tayeb H, Khayat A, Milyani H, Alsawwaf Y, Alzaben F, Koenig HG. Supernatural explanations of neurological and psychiatric disorders among health care professionals at an academic tertiary care hospital in Saudi Arabia. J Nerv Ment Dis. 2018;206(8):589-592. doi:10. 1097/NMD.0000000000000838 
14. Almuayqil S, Atkins A, Sharp B. Ranking of E-health barriers faced by Saudi Arabian citizens, healthcare professionals and IT specialists in Saudi Arabia. Health. 2016;08(10):1004-1013. doi:10.4236/ health.2016.810104

15. Atique S, Hosueh M, Fernandez-Luque L, et al. Lessons learnt from a MOOC about social media for digital health literacy. 2016 38th Annual International Conference of the IEEE Engineering in Medicine and Biology Society (EMBC); 2016.

16. Jacobs W, Amuta A, Jeon K, Alvares C. Health information seeking in the digital age: an analysis of health information seeking behavior among US adults. Cogent Soc Sci. 2017;3(1):1302785. doi:10.1080/ 23311886.2017.1302785

17. Fagerlund A, Holm I, Zanaboni P. General practitioners' perceptions towards the use of digital health services for citizens in primary care: a qualitative interview study. BMJ Open. 2019;9(5):e028251. doi:10.1136/bmjopen-2018-028251

18. Zhou L, Bao J, Setiawan IMA, Saptono A, Parmanto B. The mHealth App Usability Questionnaire (MAUQ): development and validation study. JMIR mHealth uHealth. 2019;7(4):e11500. doi:10.2196/11500

19. Ekman B. Cost analysis of a digital health care model in Sweden. PharmacoEconomics Open. 2017;2(3):347-354. doi:10.1007/s41669017-0059-7

20. Xing W, Hsu P, Chang Y, Shiau W. How does online doctor-patient interaction affect online consultation and offline medical treatment? Ind Manag Data Syst. 2019;120(1):196-214. doi:10.1108/IMDS-052019-0261

21. Likert RA. Technique for the measurement of attitudes. Arch Psychol. 1932;140:1-55.

22. Saunders M, Lewis P, Thornhill A. Research Methods for Business Students. 8th ed. Pearson; 2019.

23. Reiners F, Sturm J, Bouw LJW, Wouters EJM. Sociodemographic factors influencing the use of eHealth in people with chronic diseases. Int J Environ Res Public Health. 2019;16(4):645. doi:10.3390/ ijerph 16040645

24. Etikan I. Comparison of convenience sampling and purposive sampling. Am J Theor Appl Stat. 2016;5(1):1. doi:10.11648/j. ajtas.20160501.11

25. Walston S, Al-Harbi Y, Al-Omar B. The changing face of healthcare in Saudi Arabia. Ann Saudi Med. 2008;28(4):243-250. doi:10.5144/ 0256-4947.2008.243

26. Saquib N, Saquib J, Alhadlag A, et al. Chronic disease prevalence among elderly Saudi men. Int J Health Sci. 2017;11(5):11-16.

27. Ahmed AE, AlBuraikan DA, Almazroa HR, et al. Seventy-two-hour emergency department revisits among adults with chronic diseases: a Saudi Arabian study. Ther Clin Risk Manag. 2018;14:1423-1428. doi:10.2147/TCRM.S168763

28. Lee C, Thampi S, Lewin B, et al. Battling COVID-19: critical care and peri-operative healthcare resource management strategies in a tertiary academic medical centre in Singapore. Anaesthesia. 2020;75(7):861-871. doi:10.1111/anae.15074

29. Tan-Torres Edejer T, Hanssen O, Mirelman A, et al. Projected health-care resource needs for an effective response to COVID-19 in 73 low-income and middle-income countries: a modelling study. Lancet Glob Stud. 2020;8(11):e1372-e1379. doi:10.1016/S2214109X(20)30383-1

30. Ng K, Poon B, Kiat Puar T, et al. COVID-19 and the risk to health care workers: a case report. Ann Intern Med. 2020;172(11):766-767. doi: 10.7326/L20-0175

31. Lo S, Yong A, Sinhal A, et al. Consensus guidelines for interventional cardiology services delivery during COVID-19 pandemic in Australia and New Zealand. Heart Lung Circ. 2020;29(6):e69-e77. doi:10.1016/j.hlc.2020.04.002
32. Ma X, Vervoort D, Reddy C, Park K, Makasa E. Emergency and essential surgical healthcare services during COVID-19 in low- and middle-income countries: a perspective. Int J Surg. 2020;79:43-46. doi:10.1016/j.ijsu.2020.05.037

33. Taylor C, Fitzsimmons-Craft E, Graham A. Digital technology can revolutionize mental health services delivery: the COVID -19 crisis as a catalyst for change. Int J Eating Disord. 2020;53(7):1155-1157. doi:10.1002/eat.23300

34. Islam M, Islam I, Munim K, Islam A. A review on the mobile applications developed for COVID-19: an exploratory analysis. IEEE Access. 2020;8:145601-145610. doi:10.1109/ACCESS.2020. 3015102

35. Alsyouf A. Mobile Health for covid-19 pandemic surveillance in developing countries: the case of Saudi Arabia. Solid State Technol. 2020;63(6):2474-2485.

36. $\mathrm{MOH}$. $\mathrm{MOH}$ apps for smartphones [Internet]; 2020 [cited December 19, 2020]. Available from: https://www.moh.gov.sa/en/ Support/Pages/MobileApp.aspx. Accessed November 2, 2021.

37. O'Connor S, Hanlon P, O'Donnell CA, et al. Understanding factors affecting patient and public engagement and recruitment to digital health interventions: a systematic review of qualitative studies. $B M C$ Med Inform Decis Mak. 2016;16:120.

38. Alharbi MA. The status quo of health information technology and health information management efficiency in Saudi Arabia: a narrative review. Int $J$ Health Res Innov. 2018;6(1):11-23.

39. Kurdi R, Aljehani M, Subasi A, Qaisar S. Cloud computing based healthcare information systems: a proposal for the Kingdom of Saudi Arabia. 2017 International Conference on Electrical and Computing Technologies and Applications (ICECTA); 2017.

40. Alsahafi Y, Gay V, Khwaji A. Factors affecting the acceptance of integrated electronic personal health records in Saudi Arabia: the impact of e-health literacy. Health Inf Manag J. 2020;183335832096489. doi:10.1177/1833358320964899

41. Alkraiji AI, Jackson T, Murray I. Factors impacting the adoption decision of health data standards in tertiary healthcare organisations in Saudi Arabia. $J$ Enterp Inf Manag. 2016;29(5):650-676. doi:10.1108/JEIM-11-2014-0111

42. Ahmad A. The Impact of stakeholders on health services development: an empirical investigation on the surgical department at King Fahd General Hospital, Saudi Arabia. Int J Mark Stud. 2017;9 (1):129. doi:10.5539/ijms.v9n1p129

43. AlMubarak S, Alfayez A, Alanazi A, Alwuhaimed L, Bo Hamed S. Autonomy, accountability, and competition: the privatisation of the Saudi health care system. J Taibah Univ Med Sci. 2020;16 (2):144-151.

44. Alijedaani B, Ahmad A, Zahedi M, Babar MA. Security awareness of end-users of mobile health applications: an empirical study. Cornell University; 2020. arXiv.org arXiv:2008.13009.

45. Alanzi T. mHealth for diabetes self-management in the Kingdom of Saudi Arabia: barriers and solutions. $J$ Multidiscip Healthc. 2018;11:535-546. doi:10.2147/JMDH.S174198

46. Altulaihi B A, Alharbi K G, Alhassan A M, et al. (July 02, 2021) Physician's Perception Toward Using Telemedicine During COVID19 Pandemic in King Abdulaziz Medical City, Riyadh, Saudi Arabia. Cureus. 2021;13(7):e16107. doi:10.7759/cureus.16107

47. Bahamdan AS. Review of the psychological impact of COVID-19 pandemic on healthcare workers in Saudi Arabia. Risk Manag Healthc Policy. 2021;14:4105-4111. doi:10.2147/RMHP.S324938

48. Alhurishi S, Almutairi K, Vinluan J, Aboshaiqah A, Marie M. Mental health outcomes of healthcare providers during COVID-19 pandemic in Saudi Arabia: a cross-sectional study. Front Public Health. 2021;9:647. doi:10.3389/fpubh.2021.625523 


\section{Publish your work in this journal}

Risk Management and Healthcare Policy is an international, peerreviewed, open access journal focusing on all aspects of public health, policy, and preventative measures to promote good health and improve morbidity and mortality in the population. The journal welcomes submitted papers covering original research, basic science, clinical \& epidemiological studies, reviews and evaluations, guidelines, expert opinion and commentary, case reports and extended reports. The manuscript management system is completely online and includes a very quick and fair peer-review system, which is all easy to use. Visit http://www.dovepress.com/testimonials.php to read real quotes from published authors. 